\title{
FACTORS INFLUENCING THE TRANSITION FROM ORALITY TO LITERACY
} HILDEGARD VAN ZWEEL

\section{DEPARTMENT OF GENERAL LINGUISTICS}

UNIVERSITY OF STELLENBOSCH

\section{INTRODUCTION}

The aim of this paper is to examine some of the differences between orality and literacy, and some of the factors that may play a role in the transition from orality to literacy.

I will concentrate on the work of Walter Ong (1982) and discuss the claims he makes regarding the psychodynamics of primary orality. I must emphasise that Ong's is but one view of orality. There are other approaches, like the ideological model of Brian Street. 1

Why examine the differences between orality and literacy and the transition from one to the other? There are three possible reasons. Firstly, so-called illiteracy presents a socio-economic problem. However, this paper does not address the socio-economic problem of illiteracy. Which is not to say that it is a trivial problem. Secondly, results from an investigation into the differences between orality and literacy may provide useful insights into the oral psyche. And consequently insights into the problems people from oral societies have when making the transition to literacy. These insights may be useful to curriculum planners, language teachers and people working in adult education, who may work with persons from cultures which still retain strong oral influences. Thirdly, and perhaps most significantly, we may learn more about human cognitive development. Afterall, orality existed before literacy, it is pervasive and it is the way children acquire language.2 Ong (1982:15) argues that "Literacy can be used to reconstruct for ourselves the pristine human consciousness which was not literate 
at all. ... Such reconstruction can bring a better understanding of what literacy itself has meant in shaping man's consciousness toward and in high-technology cultures."

\section{THE DIFFERENCES BETWEEN ORALITY AND LITERACY}

Ong (1982:1) claims that thought and expression in oral cultures are different from thought and expression in literate cultures. They are organised differently. And they do not use the same types of logic.

\subsection{PRIMARY ORALITY}

At this point it may be useful to consider Ong's (1982:1-3) distinction primary orality vs. secondary orality. Primary orality characterises the (mental) state of persons with no knowledge of writing. Secondary orality, in contrast, characterises the (mental) state of persons who are literate and live in the electronic era of radio and television.

\section{$2.1 \cdot 1$}

\section{THE HOMERIC QUESTION}

Ong uses the work of the classicist Milman Parry to justify some of his claims about the differences between orality and literacy. Parry examined what is known as "the Homeric question". The Homeric question asks whether Homer wrote the Iliad and the odyssey. Parry came to the conclusion that Homer did not write the two epics. This discovery of Parry's took place at a time when other scholars had already made the following discoveries:

* Ellendt and Duntzer found that the choice of epithets in Homer's work was dependent on the hexametric line of the epics. 
Van Gennep had come to the conclusion that oral poetry was structured formulaically.

Murko had pointed out that precise verbatim memory was absent in oral tradition.

Jousse had found that there is a difference between oral and written compositions.

It was in this context that Parry came to the conclusion that "virtually every distinctive feature of Homeric poetry is due to the economy enforced on it by oral methods of composition." Parry used the following axiom to describe the composition method of the Homeric poet: the choice of words and word-forms depended on the shape of the hexameter line. This entailed that the oral poet would choose from his repertoire of epithets the epithet that best suited the metre.

Scholars, like Albert Lord who continued with Parry's work, found that the Iliad and the Odyssey consisted of standardised formulas grouped around standardised themes. It was found that other oral narratives and oral discourse around the world, also used standardised formulas and standardised themes. Thus, an oral poet would compose an epic poem or narrative by stitching together standardised themes using standardised formulas. It also became clear that oral poets did not memorise verbatim, because the retelling of a story was never exactly the same. Another point that is related to this composition method of oral poets, is the notion originality. Originality for oral poets did not necessarily reside in new ideas or new themes being presented, but rather in novel ways of stitching together wellknown themes, using well-known formulas.4 
Based on Parry's discovery, Ong (1982:23ff) makes the following claims about primary orality. Firstly, orally based thought and expression are formulaically organised. Secondly, oral poets compose their poems and narratives by stitching together standardised themes using standardised formulas.

Ong (1982:33-34), furthermore, claims that formulaic thought patterns and formulaic memory patterns are a necessity in the oral intellectual world, because all knowledge has to be structured and stored in such a way that it can be retained and retrieved effectively. He (1982:34) claims that oral memory needs demand that oral thought and expression have the following characteristics: That they be heavily rhythmic, in balanced patterns, in repetitions or antitheses, in alliteration and assonances, in epithets and other formulaic expressions, in standard thematic settings, and in proverbs. (An interesting example that ong (1982:34) cites to illustrate the rhythmic quality of oral thought, is that of ancient Armaic and Hellenic targums or holy writings, which when recited, are/were accompanied by rhythmic breathing, gestures and bilateral body symmetry.) According to ong (1982:33f) then, formulas are the basis of thought and memory in oral persons. He (1982:35) goes on to say that the use of non-formulaic and non-patterned elements when thinking, is ineffective. Heavy patterning and communal fixed formulas serve to keep memory records in oral cultures.

$2 \cdot 1 \cdot 2$

ONG'S PRELIMINARY LIST OF CHARACTERISTICS OF ORALLY BASED THOUGHT AND EXPRESSION

Besides being formulaic, Ong (1982:36-49) also describes orally based thought and expression in terms of the following nine characteristics. He (1982:36) does, however, point out that the list of characteristics is not exhaustive, but rather suggestive; 
and adds that "much more work and reflection is needed to deepen understanding of orally based thought." The nine characteristics are:

\subsubsection{Additive rather than subordinative}

Oral discourse and narratives are characterised by the frequent use of conjunctions such as and, which joins consecutive sentences. This is in contrast with written discourse which is characterised by the subordination of sentences. Ong (1982:37) cites the example of two versions of Genesis 1:1-15. The earlier version, dated 1610, was produced in a culture with massive oral residue. The Genesis portion in the earlier version is characterised by nine ands. In contrast, the later version, namely the 1970 New American Bible, only contains two ands in the corresponding portion of text. The sentences are subordinated with words like then, thus and while.

\subsubsection{Aggregative rather than analytic}

Ong (1982:38) claims that the elements of orally based thought and expression are: set phrases and epithets or formulas, such as wise Nestor and clever Odysseus. This formulaic aspect of orally based thought and expression aid the oral memory. Formulas are not characteristic of written discourse, because literates regard formulaic expressions as clichés to be avoided.

\subsubsection{Redundant or 'copious'}

Oral discourse often contains redundancies or repetitions. The reason for this is to enable the speaker and hearer to stay close to the subject. In the case of written discourse, however, redundancy and repetitions are unnecessary because the reader can go back in the text. Ong (1982:40) points out some of the advantages of redundancy: a) Big audiences in places where the acoustics are bad will benefit by repetitions. b) The speaker 
stays close to his subject and it also gives him time to organise his thoughts.

\subsubsection{Conservative or traditionalist}

Because knowledge is precious in oral cultures, it must be repeated often. In an oral culture: You only know what you can recall. As a result, oral persons will have a conservative attitude towards established knowledge. Ong (1982:41) points out that this conservative attitude "inhibits intellectual experimentation".

\subsubsection{Close to the human lifeworld}

Ong (1982:42) claims that all knowledge in oral cultures is conceptualised with close reference to the human lifeworld. He argues that this is necessary because oral cultures lack elaborate analytical categories that depend on writing. An example illustrating this characteristic, is the absence of abstract neutral lists, Rather, oral cultures place large sequences of information, like genealogies, in the context of human action and human relations. For example: $A$ begat $B$, and $B$ begat $C$, and $C$ begat $D$, or $A$ is the father of $B$, and $B$ is the father of $\mathrm{C}$, etc.

\subsubsection{Agonistically toned}

Ong (1982:43) claims that writing fosters abstraction. This gives written discourse a neutral and distanced tone. Therefore, literate persons often experience oral culture as agonistic. This agonistic element can be observed in either fullsome praise (which literates would call exaggerated or excessive praise) or blaming and name-calling. The explanation he (1982:44) gives for the agonistic tone of oral discourse is that it originates in the context of a struggle for survival. It is interesting that ong (1982:45) believes that "the agonistic dynamics of oral thought processes and expression have been central to the development of 
western culture, where they were institutionalised by the 'art' of rhetoric..."

2.1.2.7. Empathetic and participatory rather than objectively distanced

In order to learn, persons in oral cultures have to identify closely and empathetically with what has to be learnt. In contrast, literate cultures separate, disengage, and distance the knower and the known, and thus create objectivity.

\section{$2 \cdot 1 \cdot 2 \cdot 8$. Homeostatic}

Ong (1982:46) characterises oral cultures as homeostatic in the sense that these cultures maintain a dynamic equilibrium with regard to their collective memory. The argument he uses, works as follows: Because the collective memory of an oral culture is limited, only knowledge that is relevant for the present time, is stored. Knowledge that has become irrelevant, is excluded from the collective memory. The equilibrium is thus maintained by discarding what is no longer necessary or relevant. The homeostatic character of oral cultures is illustrated by the example of the Tiv people of Nigeria. When social relations among them change they adjust their genealogies accordingly, so that the genealogies reflect the new social relations.

\subsubsection{Situational rather than abstract}

Oral cultures tend to use concepts in situational frames of reference which are minimally abstract, says Ong (1982:49). That means, concepts are used with close reference to the human lifeworld. An example of situational thinking is the Greek epithet amymon, which means "beautiful-in-the-way-a-warriorready-to-fight-is-beautiful". This same epithet has been translated by literates as "blameless", which is a much more abstract concept than the original oral one. 
Ong (1982:49-57) uses A.R. Luria's work Cognitive Development: Its Cultural and Social Foundations (1976) to support his claims about oral thought processes.

Luria did extensive fieldwork with oral and somewhat literate persons, in Uzbekistan and Kirghizia in the Soviet Union, from 1931-1932. He placed the persons he interviewed on a scale ranging from illiteracy to various levels of moderate literacy. Ong (1982:50) interprets Luria's hypothetical scale and Luria's consequent conclusions, as supporting his claims that orally based intellectual processes are different from literacy based intellectual processes. On the basis of Luria's work, ong $(1982: 50)$ argues:

"The contrasts that show between illiterates and literates ....are marked and certainly significant and they show (that)... it only takes a moderate degree of literacy to make a tremendous difference in thought processes."

Luria came to the following five conclusions. Firstly, oral persons do not use abstract names. His subjects identified seometrical figures by giving them the names of objects they knew. For example, a circle would be called plate, sieve, bucket, or moon. This conclusion of Luria's supports Ong's claim that oral persons conceptualise all knowledge with close reference to the human 1 ifeworld.

Luria's second conclusion was that oral persons do not make use of abstract classification. His subjects were presented with drawings of four objects, of which three belonged to a specific category and the fourth did not. The four objects were a hammer, a saw, a hatchet, and a log. Instead of applying the classification "tool" to hammer, saw, and hatchet, they applied situational thinking. One oral person said: "rhey're all alike. 
The saw will saw the $\log$ and the hatchet will chop it into small pieces. If one of these has to go, I'll throw out the hatchet. It doesn't do as good a job as a saw..." Luria came to the conclusion that oral persons use situational thinking rather than categorial thinking. This conclusion of Luria's supports Ong's claim that oral persons tend to use concepts in situational frames that are minimally abstract.

The third conclusion Luria came to, was that oral persons do not operate with formal deductive procedures at all. When Luria's oral subjects were presented with the following syllogism; they would go beyond the information in the syllogism and apply other real-life knowledge. For example, consider one subject's answer to the following syllogism:

In the Far North, where there is snow, all bears are white.

Novaya Zembla is in the Far North and there is always snow there.

What colour are the bears?

The subject answered: "I don't know. I've seen a black bear. I've never seen any others... Each locality has its own animals". Ong (1982:53) cites other interesting research done on syllogisms. Cole and Scribner (1973) and Fernandez (1980) found "that a syllogism is self-contained: its conclusions are derived from its premises only". Ong (1982:53) adds the observation that "the syllogism is thus like a text, fixed, boxed-off, isolated". And, according to him, proves that formal deductive logic is dependent on the development of literacy.

The fourth conclusion Luria came to, is that oral persons do not formulate general definitions of objects. Requests by the 
researchers for definitions, met with resistance. Asked to explain what a tree is, one oral subject answered: "Why should I? Everyone knows what a tree is, they don't need me telling them". The oral subjects used personal, situational experience to describe objects. Real-life experience mattered a lot more than general definitions. Asked to describe a car, to people who have never seen one, one subject said: "If you get in a car and go for a drive, you'll find out". Luria's conclusion that oral persons use situational experience to describe objects provides support for two of Ong's claims namely, a) that oral persons conceptualise knowledge close to the human lifeworld, and b) that concepts are used in situational frames of reference rather than abstractly.

The fifth conclusion Luria came to, was that oral persons do little articulated self-analysis and little introspection. Oral persons identify strongly with their group. They also evaluate themselves in terms of their group. The reason for this, according to Ong (1982:54), is that self-analysis would require "a certain demolition of situational thinking", and "an isolation of the self". An example from Luria's research illustrates this point. When asked to describe himself, an oral subject replied: "We behave well - if we were bad people, no one would respect us".

Ong (1982:55) points out that the use of abstract names, abstract categories, formal logical reasoning processes, definitions, and articulated self-analysis are not characteristics of oral culture, but are the result of literate thought processes. He (1982:57) does, however, emphasise that orally based thought should not be regarded as "prelogical" or "illogical". Orally based thought and intelligence cannot be assessed using literate criteria, because the tests literates use to measure and evaluate oral thought processes and oral intelligence are based on formal 
logic. Oral persons themselves, assess intelligence as situated in operational context. For example, someone with good navigational skills will be seen as "clever". Orally based thinking is therefore not inferior, just different. Oral persons understand causal relationships. However, Ong points out that "they cannot organize elaborate concatenations of causes in the analytic kind or linear sequences which can only be set up with the help of texts". For example, "the lengthy sequences they produce, such as genealogies, are not analytic but aggregative".

\subsection{LITERACY}

Ong (1982:78) claims that "writing has transformed human consciousness". Therefore, literate persons think differently because their ways of thinking have been changed by literacy. He (1982:78) argues that writing establishes context-free language or autonomous discourse, which cannot be directly questioned or contested, because it has been detached from its author. Autonomous discourse is detached, because it is separate from a specific context, a specific speaker and a specific event.

\section{THE TRANSTTION FROM ORALITY TO LITERACY}

Ong (1982:26) remarks that oral formulaic thought and expression remains even after oral persons have become literate. He refers to Finnegan (1977:70) who is surprised when Opland observes that Xhosa poets who learn to write retain a formulaic style in their written poetry. Ong (1982:26) claims that this formulaic element is to be expected and points out that early written poetry everywhere exhibits this characteristic. He explains this phenomenon as oral habits of thought and expression that do not disappear overnight with the onset of literacy. 


\section{FACTORS WHICH MAY PLAY A ROLE IN THE TRANSITION FROM ORALITY TO LITERACY}

How can Ong's ideas about orality and literacy be applied to the language teaching situation? I believe that many language teachers work with students from backgrounds that still retain strong oral influences. And that, therefore, Ong's claims about the differences between orality and literacy should be regarded as significant. I have the following ideas, which are, however, not presented as a theory and are not empirically tested.

Firstly, the following cognitive factors may play a role in teaching students from cultures with oral residues. Students from oral backgrounds who think formulaically, might not use linear logic. Thus, when the language teacher presents a complex argument, using formal deductive logic to explain the behaviour of verbs, he/she may find that the student is not able to follow the argument. Another cognitive factor that may play a role when teaching students from an oral background is the matter of abstract categories. Students may have difficulty grasping abstract categories. For example, the category "verb" may not be understood. Or it may be understood in the example the teacher uses, but not recognised in other contexts.

Secondly, social factors related to an oral background may play a role when teaching a student from a culture with oral residue. A teacher may find that a group setting aids the learning process. Also that situational frames of reference will create empathy and facilitate the understanding process in the student.

Thirdly, psychological factors may play a role in teaching students from cultures with oral residues. If students from orally based cultures do little articulated self-analysis or introspection, they may find Eurocentric poetry and literature classes difficult to relate to. Abstract ideas about "the human 
condition" or the personal agonies of a poet may seem strange to these students. In these same literature classes, students may write an essay and receive the criticism that their work is full of clichés, unstructured, and lacking in originality. If a teacher understands the concept "originality" in oral cultures, he/she will know that standardised themes and formulas are the norm in oral epics. The teacher will also know that the linear, climactic plot is the result of literacy. (Ong 1982:142).

\section{CONCLUSION}

I don't pretend to have solutions to the problems of language teachers, but an understanding of the differences between orality and literacy may help teachers and applied linguists when working with persons from cultures with oral residues. 


\section{FOOTNOTES}

1. According to Wagner (1986:173), street (1984) "contrasts the autonomous approach with the ideological model, "which assumes that the meaning of literacy depends upon the social institutions in which it is embedded"...". The autonomous view entails "that literacy may be considered a neutral (or culture-free) technical skill or simply a mental technology which may or may not be possessed by the individual, but which has about the same general utility and consequences in each society where it exists." (Wagner 1986:172)

2. See Ong $(1982: 5-7)$ for comments on the primacy of oral language.

3. See Ong (1982:21).

4. See Ong $(1982: 22-23)$. 
http://spilplus.journals ac.ac.za/

\section{BIBLIOGRAPHY}

Ong, Walter $\mathrm{J}$. 1982

Orality and Literacy. The Technologizing of the Word. London, New York: Methuen.

Wagner, Daniel A.

1986

Review of Literacy in Theory and Practice.

Brian V. Street. New York: Cambridge University Press, 1984 in Applied Linguistics 7(2): 171-175. Oxford: Oxford University Press. 